\title{
"Smile through It!" Keeping up the Facade While Suffering from Postnatal Depressive Symptoms and Feelings of Loss: Findings of a Qualitative Study
}

\author{
Kari Vik ${ }^{1}$, Marit Hafting ${ }^{2}$ \\ ${ }^{1}$ Department for Child and Adolescent Mental Health, Sorlandet Hospital, Kristiansand, Norway \\ ${ }^{2}$ Department for Child and Adolescent Mental Health, Voss Hospital, Voss, Norway \\ Email: kari.vik@sshf.no,marit.hafting@uni.no
}

Received May $23^{\text {rd }}, 2012$; revised June $24^{\text {th }}, 2012$; accepted July $28^{\text {th }}, 2012$

\begin{abstract}
This qualitative study describes a research project in Norway comprising 15 mothers with postnatal depression and/or depressive symptoms and their experiences of loss in the early period following childbirth. During in-depth interviews, the mothers provided detailed descriptions of various loss subjects. Qualitative analysis revealed three global themes: loss of former identity, loss of self-reliance and lack of capacity for self-care. The analysis and discussions include perspectives from medicine and sociology. The descriptions may be valuable for health professionals' understanding and assessment of postnatal depressive symptoms in mothers. The findings may also help to bridge the gap between medicine and sociology; furthermore, the results demonstrate the importance of an interdisciplinary approach to this multifaceted and complex phenomenon.
\end{abstract}

Keywords: Postnatal Depression; Loss; In-Depth Interviews; Qualitative Study; Primary Health Care Services; Interdisciplinary

\section{Introduction}

The transition to motherhood comprises a range of physical, psychological and social changes both for the new mother and the family. Traditionally, the postnatal period was defined as roughly 40 days in most cultures. If economy and social status allowed, the new mother was supposed to rest, sleep, enjoy the baby and adjust to the new situation (Eberhard-Gran et al., 2003). Currently, the trend is an increasingly earlier discharge from the maternity unit. Many new mothers are discharged from the maternity unit even before breastfeeding routines are established, although it is quite common for mothers to feel insecure in caring for their newborns (Kurth et al., 2010). At home, the mothers are mostly left on their own with limited possibilities for rest and support.

In contemporary western societies, freedom of choice is valued highly (Giddens, 1991). Couples choose their spouses based on love rather than traditions. Expecting parents are challenged by many choices related to the care of the baby and must cope with the fundamental impacts of their choices on their family (Giddens, 1992). This challenge constitutes a heavy burden of responsibility. Simultaneously, impressions from popular media indicate that having a baby seems to be taken lightly in many families. Birth is represented as something that simply occurs while life continues as previously, and mothers have time and additional energy to see friends and carry on with career building and marital life as previously. Subjects such as bodily changes or loss of professional identity are often themes in the popular press along with the myth of the happy mother (James, 1998; Lloyd \& Hawe, 2003; Oakley, 1985). Support from extended families such as grandparents is replaced by greater demands on the caring abilities of fathers, reflected in social legislation and longer postpartum paternity leave periods. The triadic relationship comprising mother, father and child is strengthened and plays a more important role than previously (Hedenbro, 2006). Simultaneously, single motherhood, broken marriages and conflicts related to custody and the care of children are increasing.

Much of the existing research literature on postnatal depresssion and/or depressive symptoms (PND/S) (Matthey et al., 2001) focuses on issues such as risk factors, prevalence, effects on offspring and treatment and management. These issues are important and must be addressed. However, this focus reveals that pregnancy and childbirth are dominated by the medical discourse and might gain from considering other perspectives, such as sociology (Lewis \& Nicolson, 1998). Thurtle (1995) states that biological and psychological approaches do not present a full picture of the postpartum period and suggests that sociological approaches drawing on feminist, stress and labelling models may contribute. For example, a feminist viewpoint regarding questions of motherhood was included in a study of negative thoughts following childbirth (Hall \& Wittkowski, 2006). Such thoughts are common also among nondepressed mothers. Fisher et al. (2006) indicate the ever-increasing biomedical instrumentation over an event that in most societies was viewed as a woman-centred, non-medical event.

Many new mothers describe the perinatal period as a paradox in which they are happy to be mothers and simultaneously unhappy due to the losses in their lives resulting from the new situation: losses of autonomy and time, appearance, femininity and occupational identity (Nicolson, 1999). Sethi (1995) describes this as a dialectic process in which new mothers' experiences may comprise a dichotomy of feelings between the giving of themselves to the baby and losses of autonomy and freedom. The solution was a redefining of the self, relationships and professional goals. Stern (2004) terms the period prior to 
and following childbirth "the motherhood constellation" and states that the mother is in a life crisis that disorganises and reorganises much of her psychological life.

In a metasynthesis comprising 18 qualitative studies, Beck (2002) describes four overarching perspectives involved in PND: incongruity between expectations and the reality of motherhood, spiralling downward, pervasive loss and making gains. Pervasive loss was inter alia described as loss of autonomy and time, appearance, femininity, sexuality, occupational identity, support and control, control of negative emotions and the former self. Further, Beck emphasises that it is suitable that loss be identified before the healing grief work can begin; hence, knowledge of these phenomena can guide clinicians to differentiate and acknowledge the many forms of loss that new mothers can face.

In a qualitative study of $\mathrm{PND} / \mathrm{S}$ and video interaction guidance (VIG) carried out in Norway (Vik, 2010), a sense of loss emerged from the interview data. In this paper, we present identified aspects of the loss phenomena from rich descriptions offered by the mothers. The results presented here will supplement the body of knowledge about the loss phenomenon and $\mathrm{PND} / \mathrm{S}$.

The main aim of this paper is to present analysis of new mothers' descriptions of loss related to childbirth and PND/S. The paper also aims to bridge the gap between sociology and medicine. We attempt to do this by analysing and discussing the topic through the integration of sociological theory in a traditional medical field.

\section{Materials and Methods}

\section{Sampling Procedures}

The participants were recruited from a health centre. At a routine check-up six weeks following delivery, all new mothers completed the Edinburgh Postnatal Depression Scale (EPDS) (Cox et al., 1987), a screening instrument validated for use in Norway (Berle et al., 2003; Eberhard-Gran et al., 2001). A low cut-off score $(\geq 8)$ was chosen to secure variation in the material and PND/S. Recruitment lasted 20 months, from August 1, 2003 to April 1, 2005. Subsequently, after all identifying information was removed, the forms were sent to the first author (K. Vik, 2010), who calculated the scores. Next, she contacted the health centre for identification of the mothers who scored above the cut-off point and invited them to continue participation in the study. The sample size was estimated to be $10-15$ mothers. It was determined that 15 were necessary for variation. See Table 1 for a description of the sample.

\section{Data Collection and Study Material}

Data were collected by K. Vik and consist of in-depth semistructured interviews prior, immediately following, and six months subsequent to the VIG intervention. All 45 interviews were tape recorded and transcribed verbatim by K. Vik. The interviews lasted from 22 to 92 minutes with an average of 62 and a median value of 60 minutes. The interviews were conducted according to an interview guide with open-ended questions. The 15 participating mothers described that they felt themselves to be struggling with depression or depressive symptoms, and the mothers had scored between 8 and 19 on the EPDS screening. None of the participants was asked explicitly about experiences of loss.

\section{Analysing Methods and Procedures}

This study focused on documenting the individual mothers' account of reality rather than the objective reality itself (Smith,

Table 1.

An overview of descriptive features of the sample.

\begin{tabular}{|c|c|c|c|c|c|c|}
\hline Mother's age & Number of children & Civil status & Education & Housing situation & Baby's age $^{1}$ & EPDS-score \\
\hline 27 & 2 & M & $\mathrm{S}$ & $\mathrm{OH}$ & 6 & 10 \\
\hline 24 & 1 & M & St & $\mathrm{RF}$ & 14 & 18 \\
\hline 22 & 1 & $\mathrm{C}$ & $\mathrm{P}$ & RF & 9 & 10 \\
\hline 19 & 1 & $\mathrm{~S}$ & St & PH & 7 & 19 \\
\hline 24 & 1 & M & $\mathrm{P}$ & $\mathrm{RF}$ & 6 & 8 \\
\hline 25 & 1 & M & $\mathrm{T}$ & $\mathrm{OH}$ & 6 & 14 \\
\hline 30 & 2 & M & $\mathrm{T}$ & $\mathrm{OH}$ & 18 & 19 \\
\hline 34 & 2 & M & $\mathrm{T}$ & $\mathrm{OH}$ & 9 & 10 \\
\hline 24 & 2 & $\mathrm{C}$ & $P$ & $\mathrm{OH}$ & 9 & 11 \\
\hline 26 & 4 & M & $\mathrm{S}$ & $\mathrm{OH}$ & 7 & 15 \\
\hline 33 & 2 & M & $\mathrm{T}$ & $\mathrm{OH}$ & 8 & 8 \\
\hline 40 & 2 & M & S & $\mathrm{OH}$ & 9 & 9 \\
\hline 32 & 2 & M & $\mathrm{T}$ & $\mathrm{OH}$ & 22 & 11 \\
\hline 22 & 1 & $\mathrm{~S}$ & $P$ & RH & 20 & 15 \\
\hline 21 & 2 & $\mathrm{~S}$ & $\mathrm{P}$ & RH & 7 & 14 \\
\hline Mean 27.6 & & & & & Mean 10.5 & Mean 12.7 \\
\hline Median 26 & & & & & Median 9 & Median 11 \\
\hline
\end{tabular}

Explanations: Civil status: married $=\mathrm{M}$, co-habitant $=\mathrm{C}$, single mother $=\mathrm{S}$; Education: primary school $=\mathrm{P}$, secondary school $=\mathrm{S}$, student $=$ St, tertiary level $($ college/university) $=\mathrm{T}$; Housing situation: own detached house $=\mathrm{OH}$, rented house $=\mathrm{RH}$, rented flat $=\mathrm{RF}$, parental home $=\mathrm{PH}$; Baby's age: age of newborn (in weeks) at the time of the first interview.

${ }^{1}$ There were several reasons why some interviews did not begin immediately following recruitment, e.g., the baby was premature, the mother had accidentally taken the EPDS form with her and it was delivered several weeks later, or it took some time to find a suitable occasion. 
1999). A phenomenological approach (Sokolowski, 2000) helped the participants to provide their own stories, whereas the researchers' preconceptions are placed in brackets. We have strived to maintain a reflexive attitude towards the collection and analysis of the material. This attitude includes our own theoretical and experiential perspectives (Hammersley \& Atkinson 1983). Under these circumstances, "the loss theme" emerged from the mothers' stories but was never subject to direct questioning. Thus, an immersion/crystallisation analysing approach (Borkan 1999) was a first step in the analysing process. Then, we constructed a categorisation facilitated by thematic net- works as an analytic tool (Attride-Stirling, 2001). Thematic net- works are weblike illustrations summarising main themes that constitute pieces of texts. This manner of presenting the networks illustrates the non-hierarchal nature of the findings and emphasises the interconnectivity among them. Following further discussions and back- and forth investigations of the material, the data were condensed into three global themes: 1) Loss of former identity; 2) Loss of self-reliance; and 3) Lack of capacity for self-care. The analysing process was assisted by NVivo 8 qualitative software. We offer an example to illustrate the analysing process: Analysis of the entire text identified "insecurity" as a basic element, expressed as the mothers' insecure attitude and feelings in their experience of the organising theme of "not mastering new tasks", which was one dimension of the global theme 2, loss of self-reliance. The data were analysed by both authors in collaboration; however, the main body of work was conducted by the first author.

\section{Ethics}

The project was approved by the Regional Committee for Medical Research Ethics and the Norwegian Social Science Data Services. The participants were informed both in oral and written form before they signed a statement of consent. The participants were assessed by an experienced psychiatrist to ensure that they were referred for further treatment if needed. The mothers who declined to participate were offered other types of treatment or follow-up.

\section{Findings}

The data analysis revealed three global themes related to loss in the early postpartum period as experienced by the mothers:

1) Loss of former identity;

2) Loss of self-reliance;

3) Lack of capacity for self-care.

In this section, we explore and describe the basic elements of these global themes expressed by the mothers. Furthermore, using a phenomenological approach, thematic networks and our own theoretical background and presuppositions, we elaborate the organising categories through which these expressions are experienced as interpreted by the authors. The global themes and organising categories are illustrated in Figure 1. Both global themes and organising categories overlap each other at times. Quotes from first-time mothers (primipara) are marked with a capital $P$ in parentheses, and quotes from second-time or more (multipara) mothers are marked with (M). In addition, the ages of the mothers are added. All quotations are depersonalised.

\section{Loss of Former Identity}

"During pregnancy, of course I knew it would be hard, but I didn't know that it completely changed everything!" (P, 25). The mothers experienced the newborns' total dependence and fragility as overwhelming and felt invaded and confused. The mothers described a loss of former self for which they were not prepared, and when they compared birth with other changes in life, for example work changes, they found giving birth to be totally different. They realised that becoming and being a mother is not a role that one can escape. The mothers reflected on this; for example, some of them questioned whether their expectations might be too high. Despite these reflections, which seemed to be on a theoretical level, the mothers were not able to integrate this part of their identity. Loss of former identity is presented in the following organising categories: 1) Missing professional and social life; 2) loss of former body and 3) conflicting feelings regarding the roles of mother and partner. Loss

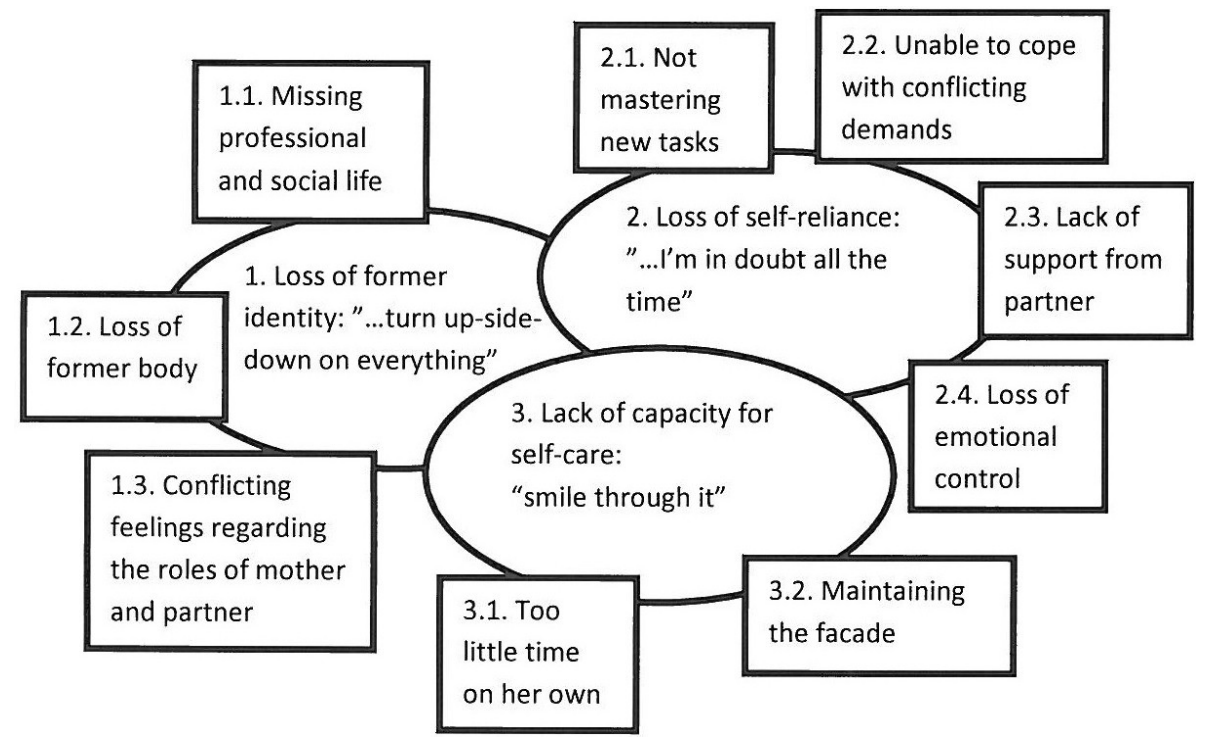

Figure 1.

Loss of identity, loss of self-reliance and lack of capacity for self-care. 
of former body comprises the physical body, the sense of the body and the body image. We present them by degrees and offer quotations from the mothers as illustrations.

\section{Missing Professional and Social Life}

The mothers reported that they missed their professional and social lives and wanted their jobs, social lives and leisure activities. Simultaneously, they found this hard to admit even to themselves and felt that those surrounding them expected them to be happy and content:

I had hoped it shouldn't be like this. During pregnancy, me and my husband talked a lot about these matters, for instance how to organise our lives so that we could bring the baby with us and go on like before. And maybe we have been taking him out too much; he is still just a few weeks, but nevertheless we prioritise social life. And I really should wish that my whole life wasn't totally changed, but it is; to a certain degree it really is. $(\mathrm{P}, 25)$

Some of the mothers expressed self-reproach when they acknowledged that they found it boring to stay at home. Disclosing this feeling was hard and at the same time, the mothers found these feelings socially unacceptable among new mothers and in society. However, the mothers really missed their jobs and their professional identities and found the transition to motherhood difficult:

I think it would have done me good to have some other plans. But many people envy me, I am aware of that, um, that I can start every day without a special timetable. But, I envy them, a little. Because I think it is important to $\cdots$ I mean I feel my brain is shrinking when the only thing I do is change nappies. $(\mathrm{M}, 33)$

This quotation also describes a feeling of worthlessness as a mother. In the mother's view, worth was connected to other tasks, for example professional life. The mothers expressed that they could no longer use their former abilities and competencies. Another dimension of the loss of social life was described by this young primipara:

What bothers me is that I know that if I hadn't had him I would still have the opportunity to have fun. Not that I'm talking about getting drunk or things like that, just to dance, dance for hours wearing high-heeled shoos, because I love to dance... I am confused; on the one hand I want my friends to call; on the other I am better off without them. $(\mathrm{P}, 19)$

\section{Loss of Former Body}

"I was not sick, just pregnant" $(\mathrm{P}, 25)$. This quotation reflects a very confusing sentiment related to the bodily changes that naturally follow pregnancy and childbirth. On the one hand, the mothers experienced this statement as true: pregnancy and childbirth are not an illness but a natural process. On the other hand, the process was followed by fundamental though varying bodily changes and altered appearances. Hence, loss of former identity was also expressed as difficulties accepting and internalising the "new" body. The mothers had difficulties adjusting to weight gain and stretch marks, and they missed their former appearances; for most of them, a slim and fit body was replaced by a feeling of being heavy, clumsy and unattractive. Again, the mothers seemed to be aware of these changes on a theoretical level, but they were nonetheless hard to accept:

I discovered myself after birth, um, being there with the child and I looked awful. I wasn't prepared at all, think of it, a woman that is slim and fit and working all the time, doing exercise and workouts, and suddenly she is supposed to sit at home with the baby, um $\cdots$ then you rapidly gain weight. $(\mathrm{P}, 24)$

\section{Conflicting Feelings Regarding the Roles of Mother and Partner}

Some mothers expressed that a feature of their frustration was confusion about and difficulties choosing between the baby and the husband. These conflicting feelings were not inflicted on the mothers externally but rather stemmed from their own confusion:

Like when we went to bed at night, on the one hand I wanted to lie close to my husband because I figured it would be so good to be myself again, without that big belly. And he was so safe and protective so I wanted him. And on the other hand I just wanted to have the baby with me in bed. So this was a huge conflict for me. It was hard to choose between the two. $(\mathrm{P}, 25)$

\section{Loss of Self-Reliance}

"The insecurity, the fact that I am in doubt all the time, this is much worse than I had imagined" (P, 22). This loss theme dominated most frequently in the immediate postpartum period. The primiparas in particular described a lack of security and self-confidence in their new role that was much worse than they had imagined. However, some of the multiparas also experienced this insecurity. For example, the multiparas had expectations of a baby similar to their firstborn, but the reality turned out to be different; additionally, they found it hard to cope with two children with different demands. The organising themes in this section are as follows: 1) not mastering new tasks; 2) unable to cope with conflicting demands; 3) lack of support from partner and 4) loss of emotional control.

\section{Not Mastering New Tasks}

"I wake up quite often just to make sure that she's alive" (M, 26). The mothers described the loss of self-reliance as anxiety, frustration and lack of self-confidence in their new role. The mothers perceived their babies as so tiny and fragile, and they didn't know how to handle the responsibility, which they found overwhelming. The mothers experienced the baby as completely dependent on them for survival and described anxiety related to the baby's life and wellbeing, for example the fear of sudden infant death syndrome. Some of the mothers described this insecurity as lack of information:

I think it's really hard; you just get a baby on your lap and that's it, and the child is supposed to be with you your whole life. A small child, it cannot express what it wants or needs. It was very hard, there was no information. (P, 24)

\section{Unable to Cope with Conflicting Demands}

The majority of mothers in this category were multipara, and the conflict was between the needs of the newborn baby and an older child, most often a toddler. The mothers described deep 
frustration in situations in which they had to choose between the baby and the older child. The mothers felt insecure and expressed that they had lost their self-reliance.

I feel that it is very hard with the toddler; he is a bit jealous so I feel a bit torn between them. I cannot concentrate a $100 \%$ on both of them. I wasn't prepared for two kids screaming and that I had to choose between them. That feeling, um, I was not prepared for how hard that feeling was, torn apart every day. And I don't know how to deal with it. $(\mathrm{M}, 27)$

\section{Lack of Support from Partner}

Loss of self-reliance expressed as lack of support from a spouse was experienced by all the mothers who were married or cohabiting. The mothers particularly longed for support that they themselves did not initiate and that they did not have to fight for (or even ask for). The mothers missed recognition from their partners and felt simultaneously disappointed and an unspoken pressure to give their spouses some space away from the family:

I really want him to stay more at home, but it is really difficult to ask. I don't want our friends, or him, to think that I am prudish; rather I want them to think that I give him the freedom he needs. (M, 27)

The mothers wanted their spouses or others to take the baby occasionally on their own initiative so that the mothers themselves would not be the one that always complained. The mothers were devastated by the responsibility and felt that they had to cope with it alone, that the partner often regarded the situation very lightly:

I get the feeling that, um, that he is only my responsibility and when that's on top of the whole situation with depression and the like it only makes things worse. It seems as though it is easy for men to think that it is mothers that have the responsibility. They can just leave and consider it for granted that I will take care of him. $(\mathrm{P}, 22)$

\section{Loss of Emotional Control}

"I feel tired and I feel that it makes me very unstable. And when I am unstable I get sad. And I feel that I get sad because I'm tired, or maybe it's the opposite" (M, 34). The mothers experienced altered moods varying from clinical depression and anxiety to distress expressed as sadness, insecurity, fear, and/or anger. Some of these feelings were concretely related to, for example, traumatic birth experiences or memories of past births, difficulties in close relationships, crises and traumas from the past, such as neglect and abuse. Other feelings were unexpected, and the mothers could not explain or understand them and found it difficult to control these feelings:

Just that little episode, I was talking on the phone and suddenly I upset my coffee cup and there was coffee all over the table and I just could not cope, no, no! I just sat down and started to cry and it was like, um, why did I do that? Why did I despair so much just because I upset the coffee cup? $(\mathrm{M}, 40)$

\section{Lack of Capacity for Self-Care}

The mothers reported that they missed the ability or opportu- nity to take care of themselves, for example, with regard to hygiene and meals. First and foremost, the newborn baby was the centre of their attention and after that, other issues came before their own needs. Lack of support from partners as described in 2.3 was also explained as a feature of the lack of capacity for self-care. The mothers claimed that if the partner had participated more, the mothers would have had the opportunity to eat, take a shower or rest. The organising themes in this section are 1) too little time on her own and 2) keeping up the facade.

\section{Too Little Time on Her Own}

"It is too little sleep. I can't sleep during the day when he is taking a nap. I am far too anxious". (M, 32) The constant lack of sleep was a characteristic of lack of self-care shared by all the mothers, who described that they felt always tired and often overwhelmed by an urge to sleep. The mothers felt it hard to lose their former independence, and even if they were prepared for this on a cognitive level, it still overwhelmed them.

So... it is all very busy and, yes I have been very tired and no matter how much I sleep there is never enough of it. Even if my husband takes him in the morning and I can sleep for long it is not enough. $(\mathrm{P}, 24)$

In addition to lack of sleep, the mothers described frustration in their everyday lives because they were unable to conduct simple everyday activities concerning their own wellbeing, such as taking a shower, going to the toilet, eating breakfast and the like. The baby was always present and demanding their attention.

There is one thing that depresses me, that is, um, that is that I cannot get out. I feel locked up. As soon as there is a chance for me to dress and get out for some fresh air then I have to feed him again, and then I have to feed myself, because that I had forgotten to do. And when I have eaten then it's his turn again, and... I feel trapped. $(\mathrm{P}, 22)$

\section{Keeping up the Facade}

"Smile through it!" said one of the mothers (M, 30), referring to her own mother. The quotation reflects some of the circumstances under which she was born and bred. It was important for this family to maintain a facade in all circumstances. This example reflects another characteristic of the mothers' reduced ability to care for themselves and to identify and recognise their own needs. Keeping up the facade stole their time and attention. To a variable degree, all the mothers in this study were busy keeping up the facade, demonstrating how happy they were and how perfectly they managed mothering and their other roles: "No one can see that I actually do not manage" (M, 33). The mothers often had visitors and were occupied with demonstrateing a clean and cosy home and serving coffee and cookies:

Well, I should have calmed down, taken things more easily and then just said that "no, we don't deal with visitors right now". But I was also proud and happy and everything, so it wasn't easy to know what was the right thing to do. But we should have just relaxed and enjoyed ourselves and the new baby, our own little family. (M, 24)

This sentiment demonstrates that it was complicated for these mothers in the immediate postpartum period to identify and recognise their needs and determine what was best for them and 
their family.

Another dimension of the facade theme was that the mothers compared themselves to other mothers, the neighbour next door, relatives or friends and in that comparison, they did not, in their own eyes, compare favourably:

Yes, that's what I do, I look at others. There is this supermammy next door and I was glad that I hadn't seen her after I extended kindergarten time for the eldest. Then by accident I ran in to her the other day and I just hurried inside. I didn't want to meet her and tell her that due to my condition I have extended kindergarten. It is difficult; it feels really bad. (M, 21)

\section{Discussion}

We have reported excerpts from 15 mothers' descriptions of various loss themes categorised into three global themes: loss of former identity, loss of self-reliance and lack of capacity for self-care. We will discuss the various themes and categories in light of their basic elements and theories and other studies on similar subjects.

Much of the loss phenomena concentrated on loss of former identity. This finding is also reported by others; for example, Davies and Welch (1986) state that being a person and being a mother can be experienced as mutually exclusive, especially when there is a high level of idealism about motherhood. The idealism lies in unspoken demands from friends, relatives, neighbours and dominating cultural beliefs expressed in the popular media and communicates that a good mother should master numerous tasks in addition to mothering shortly after childbirth (Lee, 1997). In our sample, this idea was expressed as loss of professional and social life, bodily changes and confusion over mother and spouse roles. This idealism or cultural expectation of happiness can be associated with a female "ethic of care" as described by Gilligan (1982). This ethic is to a high degree an ethic of self-sacrifice. Davies and Welch extrapolate this point, claiming the following about mothering: "however willingly this is done, the price, loss of sense of self and location in the world can be hard to cope with" (1986: p. 419).

An enormous volume of information about the transition to motherhood is available in western contemporary societies. Hence, one should presuppose that the changes regarding loss of former identity related to having and caring for a baby would be properly addressed. However, the information from health authorities is not sufficient. Lewis and Nicolson (1998) argue that it is the medical/clinical discourse on these matters, as described in the introduction, which regulates mothers' organisation of subjective experience and perception of motherhood. Another perspective is that pregnancy and childbirth are natural, and there is the societal norm that emphasises freedom of choice and individual responsibility. Brudal (2000) suggests that giving birth should be considered an existential crisis. A new identity is about to be formed, and women expand their roles to encompass the role of becoming and being a mother. This crisis is most fundamental for first-time mothers but is also experienced by multiparas. Regarding loss of the former body, the attitude expressed by some mothers of not being sick, simply pregnant is also a dominant attitude in the popular media (James, 1998); therefore, the attitude is an understandable though not realistic ideal for the mothers and many young mothers-to-be. In an Australian study, the tension between motherhood (the private sphere) and achievement (the public sphere) is explained as one source of PND. The researchers suggest that a solution to the problem is to educate the mothers and families to have a realistic view of parenting (Lloyd \& Hawe, 2003).

The second global theme in our study is loss of self-reliance, exemplified by not feeling able to master new tasks, unable to cope with conflicting demands, lack of support from spouse and loss of emotional control. Drawing on sociological theory, we state that in contemporary western societies, insecurity and risks are increasingly related to uncertainty concerning the social and existential parts of our lives (Beck 1992). This insecurity occurs on a subjective level of consciousness and identity. Giddens (1991) states that currently, identity depends on the formation of a reflexive self, which, in turn, emerges only in the presence of ontological security. The dangers threatening human beings are no longer wild beasts but the risks of not managing engagement in close relationships. Security, formerly related to family and tradition, is jeopardised by these important societal shifts that also influence the transition to motherhood and the lack of self-reliance that the mothers in this study describe.

With regard to loss of self-reliance, we focus on the third organising category in this discussion. Marital problems or conflicts most often focused on the partners' lack of support and understanding. The mothers longed for recognition and acknowledgement in their new roles and were frequently reluctant to ask for help; instead, they wanted their partner to see for himself how he could contribute and support. Morgan et al. (1997) report a similar result: "They hope their partners will read their minds, provide necessary nurture and perceive how their (the women's) needs have changed since the arrival of the baby" (p. 916). The level of satisfaction with partners' contributions to the household is a strong predictor of mothers' psychological wellbeing and pinpoints the importance of social support, especially from partners, and its vital role in buffering the effects of life events and stressors such as childbirth (Lee 1997). Therefore, awareness of this issue is of great importance in clinical practice and counselling; and in particular, the gap between the mothers' unexpressed and expressed wishes regarding what they want from their partner.

Lack of self-care is the third global theme in this study. The organising categories under this theme are: too little time on her own and keeping up the facade. Lack of self-care was particularly expressed as insufficient sleep. In preparations for motherhood, sleep is an important issue, and mothers-to-be are advised to find ways to ensure that they sleep enough. Although "everybody" understands the importance of sleep and that there is less opportunity to sleep due to night-feedings and similar tasks, the mothers prioritised, for example, keeping up the facade rather than sleeping during the day. Lack of self-care was also described as being locked up. The presence of the baby hindered the mothers in eating, taking a shower or getting some fresh air. Wood et al. (1997) state this finding as follows: "She is completely overwhelmed by the demands of her infant, and feels trapped, angry and afraid" (p. 311).

We have organised the category of keeping up the facade under the global theme lack of self-care, though it permeates all the other themes. A heavy burden related to loss is the conflict between, on the one hand societal norms, cultural beliefs and demands, and on the other hand, the lives people actually live, reflected in a very great number of references to the facade. Whether these demands are real is of less importance as they 
are perceived as real by the mothers and hence bear real consequences. Wood et al. (1997) report that "The facade of normalcy" is a distinct feature of postpartum depression. Her informants described a "former self" that focused on performance and control in their former roles. Suffering depression, the mothers no longer handled their lives and did not dare to display their misery to others. Other studies report the same need for perfection and often on behalf of self-care (Morgan et al. 1997). Additionally, nondepressed mothers have reported fear of acknowledging negative thoughts and feelings because they were frightened that it might lead to being regarded as unfit for motherhood or being labelled mentally ill (Hall \& Wittkowski, 2006).

Becoming a mother is expected to be a happy event. When new mothers suffer PND, for which the prevalence is $13 \%$ (O'Hara \& Swain, 1996) or PNDS, with a prevalence of $16 \%$ (Thio et al., 2006), the problem seems to be isolated first and foremost to the individual mother and her infant and subsequently to the father and extended family and their GP or other health institutions. The meaning that the mothers themselves give to their situation is still somewhat absent, at least in the health services that should help these women. Both experts and lay people seem to consider PND to be distinct from the social context of motherhood and childbirth. If losses of autonomy and time, appearance, femininity and sexuality and occupational identity were acknowledged and the mothers were encouraged to grieve, PND could be considered a potentially healthy process towards psychological re-integration and personal growth instead of a pathological response. Furthermore, new mothers could experience psychological re-integration and personal growth (Edhborg et al., 2005; Harris, 2003; Nicolson, 1999).

Are the loss experiences reported in this study a result of $\mathrm{PND} / \mathrm{S}$, or do the burdens of loss lead to depression? Lee (1997) claims that it is more reasonable to see PND as one end of a continuum of normal adjustment to motherhood. Nonpsychotic depression after birth is not qualitatively different from other depressions and is best understood as lack of or inadequate social support, high workloads and unrealistic expectations of motherhood. In light of previous customs and rites related to childbirth, it is evident that motherhood in contemporary western societies poses extensive adjustment problems for most women. The cultural expectation of happiness and mastery leads many new mothers to suffer a combination of work overload and guilt and causes reluctance among new mothers to share their suffering. Edborgh et al. (2005) report that depressed new mothers attempted to conceal their depressed mood because they did not dare to reveal it or they did not have anyone to speak to about this problem. When mothers do not share their concerns, perceived demands cannot be corrected by people in the new mothers' environments. The mothers in our study were clear about the solution of the loss phenomena reported here, which was to display their problems and seek support. A slogan for both mothers and health professionals may therefore be "talk through it!" in contrast to "smile through it!" For this solution to occur, there is a need to extend the strict biomedical view of pregnancy and childbirth. The three global themes in this study are closely related. The themes are all embedded in existential questions that the medical domain alone cannot answer without drawing from other perspectives, for example sociological theories. This study is a brick in the wall in the process of bridging the gap between medicine and sociology.

\section{Strengths and Limitations}

Regarding depression, the sample in this study is subclinical; as such, the findings are not transferable to the general population of new mothers. This is a limitation of the study. Nevertheless, the participants were recruited with a low EPDS cut-off value, which was chosen to secure variation in the sample with regard to symptom load. In addition, the sample was drawn from a suburb area comprising a wide range of socio-economic levels. Hence, we argue that the results are transferable to similar samples of mothers, which represent a larger group than a purely clinical one. Additionally, if we consider loss connected to childbirth as a general phenomenon that is also reported in other studies (Hall \& Wittkowski, 2006; Harris, 2003; Nicholson, 1999), we can argue that the findings are transferable to the general population of new mothers in contemporary western societies.

Both authors are mothers and grandmothers. Important input to this study derived from lengthy discussions with each other about our own experiences, discussions with friends and others, and from theoretical preferences and research in the field. In a study such as ours, with a phenomenological starting point and a qualitative interpretation and analysing process, we cannot ignore the importance of these inputs; however, we can take them into consideration, reflect on them and interpret them as data sources in the analysing process (Hammersley \& Atkinson, 1983; Orange, 1995). This reflexive attitude is a strength of the study; without such an attitude, our own lived experiences might represent the opposite, a limitation.

None of the participants was asked explicitly about experiences related to loss; the participants' accounts of this subject occurred spontaneously, as reported in the Materials and Methods section. We argue that this practice strengthens the study because it represents an assurance against data collected through leading questions. To ensure internal validity, we have attempted to display the research process by thoroughly describing the different steps in the research process.

\section{Clinical Implications}

The present study demonstrates the importance of increased awareness in the public health system regarding the complexity of loss phenomena and PND/S. Knowledge must be implemented at GPs' offices, health centres, family centres and in specialised mental health services. Preparations for an existentially different and more exhausting life should be a routine part of health visitors', midwives' and GPs' contact with pregnant women and their partners in birth preparation courses. Health workers at all levels must help mothers (and fathers) to adjust their expectations to life as new parents. Plans for the postpartum period other than to rest and care for the baby are not necessary. New mothers are successful as women if they consider responsibility for the care of the baby and themselves as a sufficient goal.

Furthermore, it is necessary to increase knowledge and consideration of the existential dimension connected to pregnancy and childbirth and to be aware that theoretical understanding of these matters is often insufficient. Such knowledge must be combined with an openness that creates trust and allows mothers to reveal their thoughts, or "talk through it!" If expectations were more realistic, and feelings of loss were simultaneously validated, then loss experiences could be integrated as a healthy part of life as a new mother. 


\section{REFERENCES}

Attride-Stirling, J. (2001). Thematic networks: An analytic tool for qualitative research. Qualitative Research, 1, 385-405.

doi: $10.1177 / 146879410100100307$

Beck, C. T. (2002). Postpartum depression: A metasynthesis. Qualitative Health Research, 12, 453-472. doi:10.1177/104973202129120016

Beck, U. (1992). Risk society: Towards a new modernity. London: Sage.

Berle, J. O., Aarre, T. F., Mykletun, A., Dahl, A. A., \& Holsten, F. (2003). Screening for postnatal depression. Validation of the Norwegian version of the Edinburgh Postnatal Depression Scale, and assessment of risk factors for postnatal depression. Journal of Affective Disorders, 76, 151-156. doi:10.1016/S0165-0327(02)00082-4

Borkan, J. (1999). Immersion/crystallization. In B. F. Crabtree, \& W. L. Miller (Eds.), Doing qualitative research (pp. 179-194). Thousand Oaks, CA: Sage.

Brudal, L. (2000). Mental reactions in connection with pregnancy, birth and the post partum period. Bergen: Fagbokforlaget.

Cox, J. L., Holden, J. M., \& Sagovsky, R. (1987). Detection of postnatal depression. Development of the 10-item Edinburgh Postnatal Depression Scale. British Journal of Psychiatry, 150, 782-786. doi:10.1192/bjp.150.6.782

Davies, B., \& Welch, D. (1986). Motherhood and feminism: Are they compatible? The ambivalence of mothering. Australian and New Zealand Journal of Sociology, 22, 411-426. doi:10.1177/144078338602200305

Eberhard-Gran, M., Eskild, A., Tambs, K., Schei, B., \& Opjordsmoen, S. (2001). The Edinburgh Postnatal Depression Scale: Validation in a Norwegian community sample. Nordic Journal of Psychiatry, 55, 113-117. doi:10.1080/08039480151108525

Eberhard-Gran, M., Nordhagen, R., Heiberg, E., Bergsjo, P., \& Eskild, A. (2003). Postnatal care in a cross-cultural and historical perspective. Tidsskrift for Norsk Laegeforening, 123, 3553-3556.

Edhborg, M., Friberg, M., Lundh, W., \& Widstrom, A. M. (2005). "Struggling with life": Narratives from women with signs of postpartum depression. Scandinatian Journal of Public Health, 33, 261267. doi:10.1080/14034940510005725

Fisher, C., Hauck, Y., \& Fenwick, J. (2006). How social context impacts on women's fears of childbirth: A Western Australian example. Social Science and Medicine, 63, 64-75. doi:10.1016/j.socscimed.2005.11.065

Giddens, A. (1991). Modernity and self-identity: Self and society in the late modern age. Cambridge: Polity Press.

Giddens, A. (1992). The transformation of intimacy: Sexuality, love and eroticism. Oxford: Polity Press.

Gilligan, C. (1982). In a different voice: psychological theory and women's development. London: Harvard University Press.

Hall, P. L., \& Wittkowski, A. (2006). An exploration of negative thoughts as a normal phenomenon after childbirth. Journal of Midwifery and Women's Health, 51, 321-330. doi:10.1016/j.jmwh.2006.03.007

Hammersley, M., \& Atkinson, P. (1983). Ethnography: Principles in practice. London: Tavistock.

Harris, T. (2003). Review of Postnatal depression: Facing the paradox of loss, happiness and motherhood. Journal of Child Psychology and Psychiatry, 44, 930-931. doi:10.1111/1469-7610.00176_10

Hedenbro, M. (2006). The family triad: The interaction between the child, its mother, and father from birth to the age of 4 years old. Ph.D. Thesis, Stockholm: Karolinska Institutet.
James, K. (1998). The depressed mother: A practical guide to treatment and support. London: Cassell.

Kurth, E., Spichiger, E., Zemp, S. E., Biedermann, J., Hosli, I., \& Kennedy, H. P. (2010). Crying babies, tired mothers-Challenges of the postnatal hospital stay: An interpretive phenomenological study. BMC Pregnancy and Childbirth, 10, 21. doi:10.1186/1471-2393-10-21

Lee, C. (1997). Social context, depression, and the transition to motherhood. British Journal of Health Psychology, 2, 93-108. doi:10.1111/j.2044-8287.1997.tb00527.x

Lewis, S. E., \& Nicolson, P. (1998). Talking about early motherhood: Recognizing loss and reconstructing depression. Journal of Reproductive and Infant Psychology, 16, 177-197. doi: $10.1080 / 02646839808404567$

Lloyd, B., \& Hawe, P. (2003). Solutions forgone? How health professionals frame the problem of postnatal depression. Social Science and Medicine, 57, 1783-1795. doi:10.1016/S0277-9536(03)00061-3

Morgan, M., Matthey, S., Barnett, B., \& Richardson, C. (1997). A group programme for postnatally distressed women and their partners. Journal of Advanced Nursing, 26, 913-920. doi:10.1046/j.1365-2648.1997.00433.x

Nicolson, P. (1999). Loss, happiness and postpartum depression: The ultimate paradox. Canadian Psychology/Psychologie Canadienne, 40, $162-178$.

O'Hara, M. W., \& Swain, A. M. (1996). Rates and risk of postpartum depression-A meta-analysis. International Review of Psychiatry, 8, 23-54.

Oakley, A. (1985). Doctors, maternity patients and social scientists. Birth: Issues in Perinatal Care and Education, 12, 161-166.

Orange, D. M. (1995). Emotional understanding: studies in psychoanalytic epistemology. New York: Guilford Press.

Sethi, S. (1995). The dialectic in becoming a mother: Experiencing a postpartum phenomenon. Scandinavian Journal of Caring Sciences, 9, 235-244.

Smith, J. A. (1999). Identity development during the transition to motherhood: An interpretive phenomenological analysis. Journal of Reproductive and Infant Psychology, 17, 281-299. doi:10.1080/02646839908404595

Sokolowski, R. (2000). Introduction to phenomenology. Cambridge: Cambridge University Press.

Stern, D. N. (2004). The motherhood constellation: Therapeutic approaches to early relational problems. In A. J. Sameroff, S. C. McDonough, \& K. L. Rosenblum (Eds.), Treating parent-infant relationship problems: Strategies for intervention (pp. 29-42). New York: Guilford Press.

Thio, I. M., Oakley Browne, M. A., Coverdale, J. H., \& Argyle, N. (2006). Postnatal depressive symptoms go largely untreated: A probability study in urban New Zealand. Social Psychiatry and Psychiatric Epidemiology, 41, 814-818. doi:10.1007/s00127-006-0095-6

Thurtle, V. (1995). Post-natal depression: The relevance of sociological approaches. Journal of Advanced Nursing, 22, 416-424. doi:10.1046/j.1365-2648.1995.22030416.x

Vik, K. (2010). "From the outside looking in": A phenomenological study of postnatal depression, mother-infant interaction and video guidance. Ph.D. Thesis, Unipub., Oslo: University of Oslo.

Wood, A. F., Thomas, S. P., Droppleman, P. G., \& Meighan, M. (1997). The downward spiral of postpartum depression. American Journal of Maternal Child Nursing, 22, 308-316. doi:10.1097/00005721-199711000-00007 